\title{
TITLE:
}

\section{Iron-catalyzed diboration and carboboration of alkynes.}

$\operatorname{AUTHOR}(S)$ :

Nakagawa, Naohisa; Hatakeyama, Takuji;

Nakamura, Masaharu

\section{CITATION:}

Nakagawa, Naohisa ...[et al]. Iron-catalyzed diboration and

carboboration of alkynes.. Chemistry - A European Journal 2015, 21(11): 4257-4261

ISSUE DATE:

2015-03-09

URL:

http://hdl.handle.net/2433/207522

\section{RIGHT:}

This is the accepted version of the following article: Nakagawa, N., Hatakeyama, T. and Nakamura, M. (2015), IronCatalyzed Diboration and Carboboration of Alkynes. Chem. Eur. J., 21:4257-4261, which has been published in final form at http://dx.doi.org/10.1002/chem.201406595. This article may be used for non-commercial purposes in accordance with Wiley Terms and Conditions for Self-Archiving.: The full-text file will be made open to the public on 27 February 2016 in accordance with publisher's 'Terms and Conditions for Self-Archiving'.: この論文は出版社版でありま せん。引用の際には出版社版をご確認ご利用ください。; This is not the published version. Please cite only the published version. 


\title{
Iron-Catalyzed Diboration and Carboboration of Alkynes**
}

\author{
Naohisa Nakagawa ${ }^{[a, b]}$, Takuji Hatakeyama ${ }^{[a, c]}$, and Masaharu Nakamura ${ }^{\left.{ }^{[a]}\right]}$
}

\begin{abstract}
We have developed an iron-catalyzed diboration reaction of alkynes with bis(pinacolato)diboron $\left(\mathrm{B}_{2} \mathrm{pin}_{2}\right)$ and external borating agents $\left(\mathrm{MeOB}(\mathrm{OR})_{2}\right)$, affording diverse symmetrical or unsymmetrical cis-1,2-diborylalkenes. The simple protocol for the diboration reaction can be extended to the iron-catalyzed carboboration of alkynes with primary and unprecedented secondary alkyl halides, affording various tetrasubstituted monoborylalkenes in a highly stereoselective manner. DFT calculations indicate that a boryliron intermediate adds across the triple bond of an alkyne to afford an alkenyliron intermediate, which can react with electrophiles, the borylation and alkylation agents. In situ trapping experiments support the intermediacy of the alkenyl iron species.
\end{abstract}

With the development of Suzuki-Miyaura cross-coupling reactions, alkenylboron compounds have attracted the attention as the key intermediates for the synthesis of diverse functional molecules for use as electronic materials and bioactive natural products. ${ }^{[1]}$ Diborylalkenes are particularly attractive building blocks for substituted alkenes ${ }^{[2]}$ and $\pi$-extended polyarenes, ${ }^{[3]}$ and their expedient synthesis has attracted much attention from synthetic chemists. The transition-metal-catalyzed diboration of alkynes has been investigated intensively ${ }^{[4]}$ since its discovery by Suzuki and Miyaura, ${ }^{[5 a]}$ and diverse transition metals such as platinum, cobalt, iridium, copper, and gold proved to be effective catalysts $^{[5]}$ (Scheme 1-A, upper reaction). Recently, coppercatalyzed diboration of alkynes has been extended to a novel carboboration reaction, ${ }^{[6,7]}$ furnishing diverse tetrasubstituted borylalkenes, ${ }^{[7 \mathrm{~d}-\mathrm{h}]}$ which are valuable synthetic intermediates (Scheme 1-A, lower reaction). The discovery of a new diboration and carboboration catalyst has enhanced the synthetic efficacy of the reaction. In this communication, we report that simple iron salts, which are one of the most promising practical catalysts, can catalyze the diboration and carboboration of internal alkynes (Scheme 1-B). The trapping experiments and DFT calculations suggest that the diboration and carboboration reactions occur

[a] N. Nakagawa, Prof. Dr. T. Hatakeyama, Prof. Dr. M. Nakamura International Research Center for Elements Science, Institute for Chemical Research

Kyoto University, Uji, Kyoto, 611-0011 (Japan)

Fax: (+81) 774-38-3186

E-mail: masaharu@scl.kyoto-u.ac.jp

Department of Energy and Hydrocarbon Chemistry, Graduate

School of Engineering, Kyoto University, Nishikyo-ku, Kyoto 615-

8510, Japan.

[b] N. Nakagawa

CREST, Japan Science and Technology Agency (JST)

[c] Prof. Dr. T. Hatakeyama

Elements Strategy Initiative for Catalysts and Batteries (ESICB),

Kyoto University, Katsura, Kyoto 615-8520 (Japan)

PRESTO, Japan Science and Technology Agency (JST)

Current address: School of Science \& Technology, Department of Chemistry, Kwansei Gakuin University, 2-1 Gakuen, Sanda, Hyogo, 669-1337 (Japan)

Supporting information for this article is given via a link at the end of the document.
(A) Previous works: Transition-metal-catalyzed diboration of alkynes and copper-catalyzed carboboration of alkynes

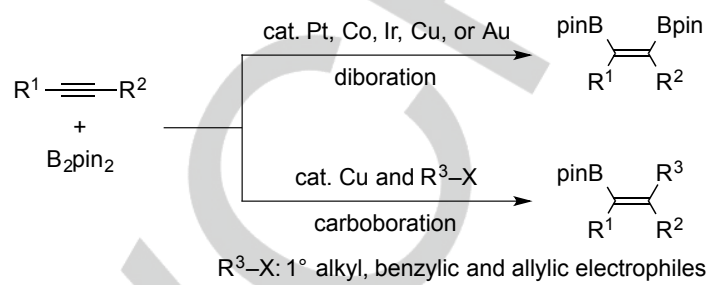

(B) This work: Iron-catalyzed diboration and carboboration of alkynes

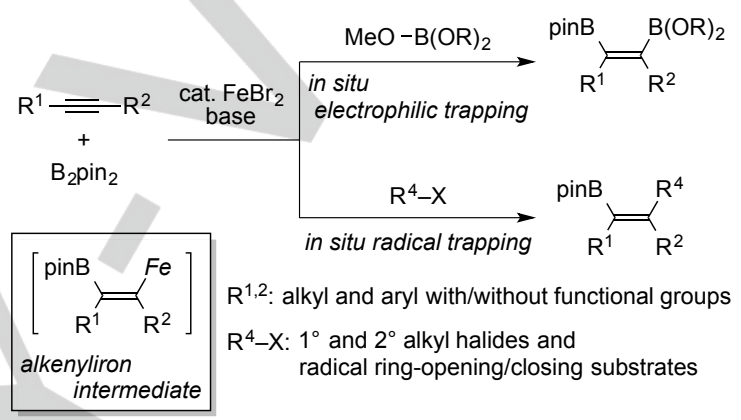

Scheme 1. Transition-metal-catalyzed diboration and carboboration of alkynes. through the formation of an alkenyliron species, which reacts with borating agents and unactivated alkyl halides, respectively, to provide the above two reactions, which have not been achieved by the existing methods.

Based on our previous studies on iron-catalyzed crosscoupling $^{[8,9]}$ and carbometalation reactions, ${ }^{[10]}$ we screened iron catalysts and reaction conditions and found that a simple iron salt can catalyze the diboration reaction of alkynes ${ }^{[11]}$ under particular conditions: In the presence of $10 \mathrm{~mol} \% \mathrm{FeBr}_{2}, 10$ mol\% LiOMe, and 1.5 equiv of 2-methoxy-4,4,5,5-tetramethyl1,3,2-dioxaborolane (MeOBpin) 3a, the diboration reaction of 4octyne 1 with bis(pinacolato)diboron $\left(\mathrm{B}_{2} \mathrm{pin}_{2}\right) 2$ afforded cis-1,2diborylalkene $\mathbf{4 a}$ in $99 \%$ yield with exclusive cis-selectivity (Table 1, optimal conditions). Table 1 summarizes the effects of deviating from the optimal conditions. In the absence of the iron catalyst, no reaction occurred (entry 2). A reduced catalyst loading afforded $\mathbf{4 a}$ in a sufficient yield (93\%), albeit with the formation of $4 \%$ of the corresponding hydroboration product ${ }^{[12]}$ (entry 3 ). The counteranions $(\mathrm{I}$ and $\mathrm{Cl}$ ) of the iron precatalyst strongly affected the diboration reaction to decrease the yield (entries 4 and 5). $\mathrm{FeBr}_{3}$ also worked as an efficient catalyst and afforded $\mathbf{4 a}$ in $92 \%$ yield (entry 6 ). The base, LiOMe, was essential for the reaction (entry 7). Increasing the amount of LiOMe $(20 \mathrm{~mol} \%)$ led to a faster conversion, but lowered the overall yield of $4 a$ (entry 8 ). The use of other alkali metal alkoxides also afforded $\mathbf{4 a}$ in high yields (entries 9-11). In the absence of MeOBpin $3 a$, the yield of $4 a$ decreased to $53 \%$, and 1 was recovered in $36 \%$ yield (entry 12 ).

We next investigated diverse alkynes and found that the reactions of internal alkynes afforded the corresponding cis1,2-diboryl alkenes in good yields and with excellent stereoselectivity (Scheme 2 ). ${ }^{[13]}$ The reactivity of alkynes was 
highly influenced by the terminal substituents: The reactions of

Table 1. Effect of reaction parameters on iron-catalyzed diboration of 4-octyne.

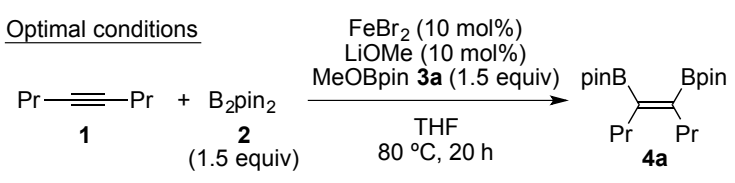

\begin{tabular}{|c|c|c|c|}
\hline Entry $^{[a]}$ & Changes from the optimal conditions & $\begin{array}{l}\text { Yield of } \\
4 \mathbf{a}[\%]^{[b]}\end{array}$ & $\begin{array}{l}\text { Recovery } \\
\text { of } 1[\%]^{[b]}\end{array}$ \\
\hline 1 & None & 99 & 0 \\
\hline 2 & Without $\mathrm{FeBr}_{2}$ & 0 & 99 \\
\hline 3 & $5 \mathrm{~mol} \%$ of $\mathrm{FeBr}_{2}$ and $\mathrm{LiOMe}, 40 \mathrm{~h}$ & $93^{[c]}$ & 0 \\
\hline 4 & $\mathrm{Fel}_{2}$ & 55 & 15 \\
\hline 5 & $\mathrm{FeCl}_{2}$ & 5 & 88 \\
\hline 6 & $\mathrm{FeBr}_{3}$ & 92 & 0 \\
\hline 7 & without LiOMe & 0 & 98 \\
\hline 8 & $20 \mathrm{~mol} \%$ of LiOMe, $9 \mathrm{~h}$ & $87^{[d]}$ & 0 \\
\hline 9 & $\mathrm{LiOtBu}$ & 63 & 33 \\
\hline 10 & $\mathrm{NaOMe}, 48 \mathrm{~h}$ & 96 & 0 \\
\hline 11 & $\mathrm{KOMe}, 48 \mathrm{~h}$ & 99 & 0 \\
\hline 12 & without 3a & 53 & 36 \\
\hline
\end{tabular}

[a] Reactions were carried out on a $0.50 \mathrm{mmol}$ scale. [b] Yields were determined by quantitative GC analyses using decane as an internal standard. [c] The hydroboration product was obtained in ca. $4 \%$ yield. [d] Yield was determined by ${ }^{1} \mathrm{H}$ NMR analysis using 1,1,2,2-tetrachloroethane as an internal standard. The hydroboration product was obtained in $6 \%$ yield.

internal alkynes with alkyl substituents afforded the desired diborylalkenes in good-to-excellent yields (4a-4d). Because aryl or bulky alkyl substituents were found to retard the diboration reaction under the optimal conditions, we screened solvents and found that dibutyl ether $\left(\mathrm{Bu}_{2} \mathrm{O}\right)$ is an effective solvent in these cases. For example, diborylalkenes $\mathbf{4 e}$ and $\mathbf{4 f}$ were obtained successfully in $\mathrm{Bu}_{2} \mathrm{O}$, but not in THF. We assume that $\mathrm{Bu}_{2} \mathrm{O}$, a weaker coordinating solvent than THF, does not hamper the coordination of alkynes to the iron center (see the DFT calculations shown below). Similarly, the reactions of monoarylsubstituted internal alkynes in $\mathrm{Bu}_{2} \mathrm{O}$ afforded the desired diborylalkenes $\mathbf{4 g} \mathbf{- 4 i}$ in fair-to-good yields. Notably, reactive functional groups such as $\mathrm{C}_{s p 2}-\mathrm{Br}$ and ethyl ester remained intact under the reaction conditions ( $4 \mathbf{h}$ and $\mathbf{4 i}$ ).

In the present study, the diboration reaction proceeded smoothly with an additional borating agent. To understand the role of the borating agent, we conducted the diboration of 1 in the presence of 2-methoxy-5,5-dimethyl-1,3,2-dioxaborinane 3b (MeOBnep) (Scheme 3). MeOBnep $\mathbf{3 b}$ participated in the diboration reaction to afford an unsymmetrical diborylalkene $\mathbf{4 j}$ as a major product. Meanwhile, only a small amount of symmetrical diborylalkene $4 a$ was observed. This result suggests that the second incorporation of the boryl unit into 1 occurs by an electrophilic substitution reaction with $3 \mathbf{a}$ or $3 \mathbf{b} .^{[14]}$

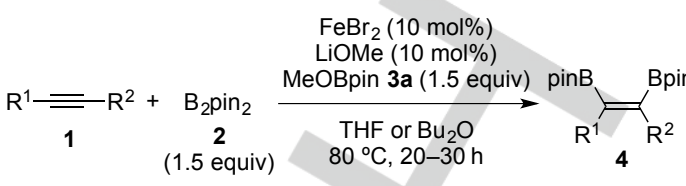

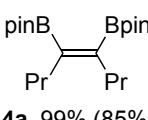

4a, $99 \%(85 \%)$ in THF

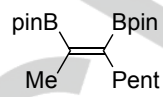

4b, $62 \%$ (59\%) in THF

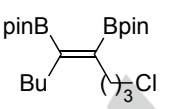

4d, $80 \%(71 \%)$ in THF

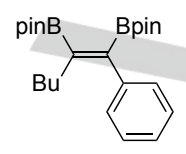

4g, $56 \%(51 \%)$ in $\mathrm{Bu}_{2} \mathrm{O}$
pinB Bpin

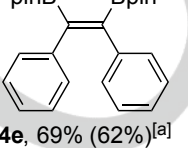

4e, $69 \%(62 \%)$
in $\mathrm{Bu}_{2} \mathrm{O}^{[b]}$

[0\% in THF]

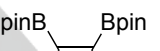

$\underbrace{\text { Bpin }}_{t_{2} \text { OTBS }}$

4c, $85 \%(74 \%)$ in THF pinB Bpin

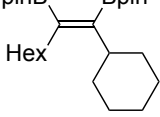

4f, $92 \%(82 \%)$ in $\mathrm{Bu}_{2} \mathrm{O}^{[c]}$

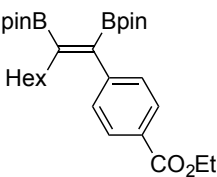

$4 \mathrm{i}, 78 \%(75 \%)$
Scheme 2. Iron-catalyzed diboration of diverse alkynes. Reactions were carried out on a $1.0 \mathrm{mmol}$ scale. Yields were determined by ${ }^{1} \mathrm{H}$ NMR analyses using 1,1,2,2-tetrachloroethane as an internal standard. Isolated yields are given in parentheses. [a] $85 \%$ cis-selectivity was confirmed by GC and ${ }^{1} \mathrm{H}$ NMR analyses. [b] Reaction was carried out at $100{ }^{\circ} \mathrm{C}$ and stirred for $12 \mathrm{~h}$. [c] $20 \mathrm{~mol} \%$ of $\mathrm{FeBr}_{2}$ and $20 \mathrm{~mol} \%$ of LiOMe were used.

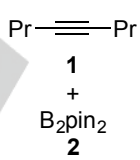

(1.5 equiv)

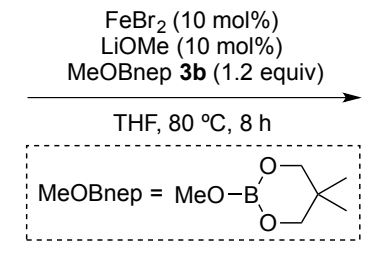

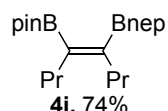

$4], 74 \%$

$(82 \%$ NMR $)$

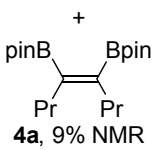

Scheme 3. Diboration of 4-octyne in the presence of MeOBnep.

Based on our previous work on iron-catalyzed crosscoupling reactions, we envisaged that a carbon electrophile such as unactivated alkyl halides could also trap the alkenyliron intermediate in a stereospecific manner. ${ }^{[15]}$ In the presence of alkyl halides 5 and a stoichiometric amount of LiOMe, the carboboration reaction occurred preferentially, affording monoborylalkenes 6 (Scheme 4). Notably, a secondary alkyl bromide also participated in the present iron-catalyzed reaction to afford the corresponding carboboration product $6 \mathbf{c}^{[16]}$ The carboboration of 1-phenyl-1-hexyne with 2 and bromocyclohexane proceeded in a regioselective manner to some extent. ${ }^{[17]}$

We assumed that the carboboration of secondary alkyl bromide involves the homolytic cleavage of the $\mathrm{C}-\mathrm{Br}$ bond, as observed in the previously reported iron-catalyzed crosscoupling reactions of alkyl halides. ${ }^{[8,9,15]}$ To confirm the intermediacy of alkyl radical species, the carboboration reaction was conducted using (cyclopropyl)methyl bromide 7 (Scheme 5A). The reaction afforded ring-opened monoborylalkene $\mathbf{8 a}$ as the sole coupling product. In contrast, the copper-catalyzed 
carboboration of an alkyne with 7 afforded allyl(cyclopropyl) monoborylalkene such as 8 b through an $\mathrm{S}_{\mathrm{N}} 2$ pathway. ${ }^{[7]}$ Carboboration using diethyl 2-allyl-2-(2-bromoethyl)malonate $\mathbf{9}$, possessing a terminal double bond, was accompanied by a cyclization reaction (Scheme 5-B). These results strongly indicate that iron-catalyzed carboboration involves the formation of alkyl radical species from alkyl halides $\mathbf{7}$ and $\mathbf{9}$.

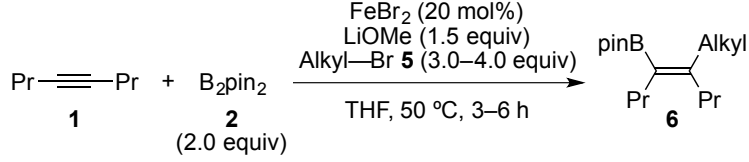

$$
\begin{aligned}
& \text { (n) }
\end{aligned}
$$

Scheme 4. Iron-catalyzed carboboration of 4-octyne. Reactions were carried out on a $0.50 \mathrm{mmol}$ scale. Yields were determined by ${ }^{1} \mathrm{H}$ NMR analyses using 1,1,2,2-tetrachloroethane as an internal standard. Isolated yields are given in parentheses.

(A) Radical ring-opening reaction using (cyclopropyl)methyl bromide

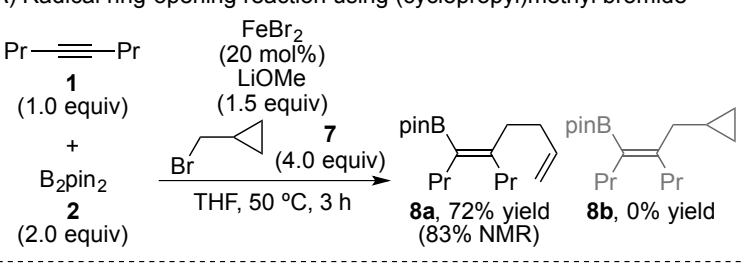

(B) Radical cyclization reaction using diethyl 2-allyl-2-(2-bromoethyl)-malonate

$$
\begin{aligned}
& \mathrm{FeBr}_{2}
\end{aligned}
$$

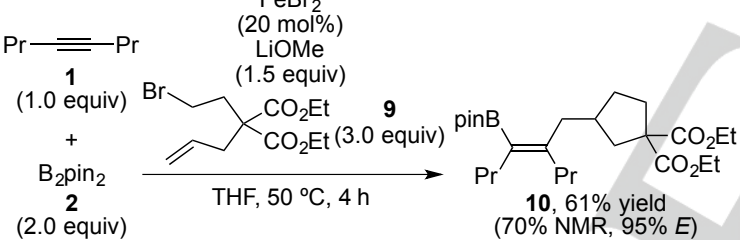

Scheme 5. Radical clock experiments.

Scheme 6 shows a plausible reaction mechanism based on the results obtained: $\mathrm{FeBr}_{2}$ initially undergoes transmetalation with LiOMe to form methoxyiron(II) intermediate $11,{ }^{[18]}$ which reacts with $\mathrm{B}_{2}$ pin ${ }_{2}$ to afford boryliron(II) intermediate 12 . The coordination of an alkyne to intermediate 12 followed by the insertion of alkyne to the $\mathrm{Fe}-\mathrm{B}$ bond generates a reactive alkenyliron(II) intermediate 13. Then, intermediate 13 undergoes an electrophilic substitution reaction with a borating agent, MeOBpin or MeOBnep, affording the diboration product cisselectively and starting methoxyiron(II) intermediate 11, thus completing the catalytic cycle. The presence of an alkyl electrophile may divert intermediate 13 into the carboboration reaction by the formation of alkyl radical species.

To evaluate the postulated pathway shown in Scheme 6, we performed a set of DFT calculations to determine the energetically feasible reaction pathway ${ }^{[19]}$ that connect iron alkoxide models $\mathbf{A}$ (dimer) and $\mathbf{B}$ (monomer) to alkenyl iron intermediate $\mathbf{H}$ (Scheme 7). Monomer $\mathbf{B}$ and $\mathbf{B}_{2} \mathrm{pin}_{2}$ form adduct $\mathbf{C}$, in which the methoxy and pinacol oxygen atoms coordinate to one of the boron atoms and iron, respectively. The transfer of the methoxy group from the iron center to the other boron atom occurs through $\mathbf{T S} \mathbf{S}_{\mathrm{CD}}$ with a small activation energy $(1.1 \mathrm{kcal} / \mathrm{mol})$, forming borate intermediate $\mathbf{D}$. Intermediate $\mathbf{D}$ interconverts to intermediate $\mathbf{E}$ with the loss of the coordination of the pinacol oxygen atom to the iron center and facilitates intramolecular $\sigma$ -

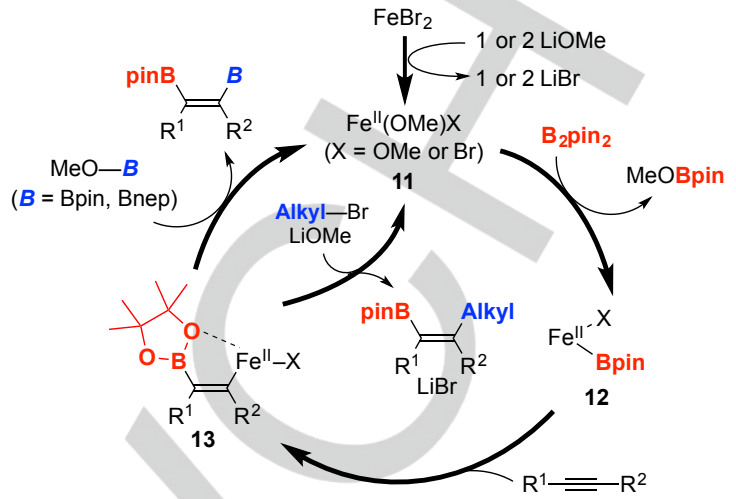

Scheme 6. Plausible pathway for iron-catalyzed diboration and carboboration reactions.

bond metathesis between the $\mathrm{Fe}-\mathrm{O}$ and $\mathrm{B}-\mathrm{B}$ bonds through $\mathbf{T S}_{\mathrm{EF}}$ to afford methoxyiron intermediate $\mathbf{F}$. The ligand exchange of the iron center from MeOBpin to 2-butyne affords alkyne $\pi$ complex G. Borylmetalation proceeds via $\mathbf{T S}_{\mathrm{GH}}$ with 10.8 $\mathrm{kcal} / \mathrm{mol}$ activation energy; this TS is the highest energy barrier in the entire process $(+21.2 \mathrm{kcal} / \mathrm{mol}$ compared to $\mathbf{A})$. The synborylmetalation reaction leads to the stereoselective formation of alkenyliron(II) intermediate $\mathbf{H}$ with $26.8 \mathrm{kcal} / \mathrm{mol}$ exothermicity. Intermediate $\mathbf{H}$ may undergo an electrophilic trapping reaction with MeOBpin to afford 1,2-cis-diborylalkene and regenerate starting complex $\mathbf{B}$, thus completing the catalytic cycle.

$$
\begin{aligned}
& \text { C. } \\
& \downarrow \Delta \mathrm{G}^{\ddagger}=+4.3
\end{aligned}
$$

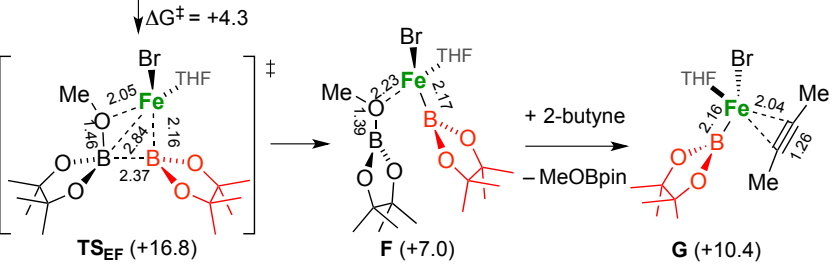

$$
\begin{aligned}
& \text { (-36.7) }
\end{aligned}
$$

Scheme 7. DFT pathway for the iron-catalyzed diboration reaction. Gibbs free energies $(\Delta G$, calculated at the MP2/6-311G(d)//B3LYP/6-31G(d) level) relative to $\mathbf{A}$ are given in $\mathrm{kcal} / \mathrm{mol}$ in parentheses. 
In summary, we developed novel iron-catalyzed diboration and carboboration reactions of internal alkynes, featuring exclusive cis-selectivity and high chemoselectivity, without using any precious metals and ligands. The synthetic advantages of our protocol over the conventional ones were demonstrated by unsymmetrical diboration and carboboration using a secondary alkyl halide. Moreover, the intermediacy of alkyl radical species enabled us to develop ring-opening and ring-closing carboboration reactions. The results of DFT calculations indicate that the reaction involves a methoxyiron species, which undergoes transmetalation with $\mathrm{B}_{2} \mathrm{pin}_{2}$ to form a boryliron intermediate, followed by the insertion of an alkyne. Further investigation is underway in our laboratory to expand the synthetic scope of these reactions and to elucidate the detailed mechanism and nature of boryliron intermediates.

\section{Acknowledgements}

This research is granted by the Japan Society for the Promotion of Science (JSPS) through the "Funding Program for Next Generation World-Leading Researchers (NEXT Program)," initiated by the Council for Science and Technology Policy (CSTP), and also supported in part by the Japan Science and Technology Agency (JST), the Core Research for Evolutional Science and Technology (CREST 1102545) program, and Ministry of Education, Culture, Sports, Science and Technology, Japan (MEXT) program "Elements Strategy Initiative to Form Core Research Center". We thank Mr. Masayoshi Jin (Daiichi Sankyo Co., Ltd.) for trace-metal analyses.

\section{Keywords: alkyl halides • alkynes • carboboration • diboration •} iron

[1] Boronic Acids, 2nd ed. (Ed.: D. G. Hall), Wiley-VCH, Weinheim, 2011

[2] a) P. Kraft, W. Tochtermann, Liebigs Ann. Chem. 1994, 827-830; b) T. Ishiyama, M. Yamamoto, N. Miyaura, Chem. Lett. 1996, 1117-1118; c) S. D. Brown, R. W. Armstrong, J. Am. Chem. Soc. 1996, 118, 63316332.

[3] a) M. W. Carson, M. W. Giese, M. J. Coghlan, Org. Lett. 2008, 10, 2701-2704; b) M. Shimizu, I. Nagao, Y. Tomioka, T. Hiyama, Angew. Chem. 2008, 120, 8216-8219; Angew. Chem. Int. Ed. 2008, 47, 80968099; c) H. Yoshida, Y. Asatsu, Y. Mimura, Y. Ito, J. Ohshita, K. Takaki, Angew. Chem. 2011, 123, 9850-9853; Angew. Chem. Int. Ed. 2011, 50 9676-9679; d) K. Yabari, S. Moussa, B. Ben Hassine, P. Retailleau, A Voituriez, A. Marinetti, Angew. Chem. 2012, 124, 6852-6856; Angew. Chem. Int. Ed. 2012, 51, 6748-6752.

[4] For recent reviews, see: a) N. Miyaura, Bull. Chem. Soc. Jpn. 2008, 81, 1535-1553; b) J. Takaya, N. Iwasawa, ACS. Catal. 2012, 2, 1993-2006.

[5] For selected example of platinum-catalyzed reaction, see: a) T. Ishiyama, N. Matsuda, N. Miyaura, A. Suzuki, J. Am. Chem. Soc. 1993 115, 11018-11019; For cobalt-catalyzed reaction, see: b) C. J. Adams, R. A. Baber, A. S. Batsanov, G. Bramham, J. P. H. Charmant, M. F. Haddow, J. A. K. Howard, W. H. Lam, Z. Lin, T. B. Marder, N. C. Norman, A. G. Orpen, Dalton Trans. 2006, 1370-1373; For iridiumcatalyzed reaction, see: c) N. Iwadate, M. Suginome, J. Am. Chem. Soc 2010, 132, 2548-2549. For copper-catalyzed reaction, see: d) $\mathrm{H}$. Yoshida, S. Kawashima, Y. Takemoto, K. Okada, J. Ohshita, K. Takaki, Angew. Chem. 2012, 124, 239-242; Angew. Chem., Int. Ed. 2012, 51, 235-238. For gold-catalyzed reaction, see: e) Q. Chen, J. Zhao, Y.
Ishikawa, N. Asao, Y. Yamamoto, T. Jin, Org. Lett. 2013, 15, 57665769 .

[6] For recent review, see: R. Alfaro, A. Parra, J. Alemán, M. Tortosa, Synlett 2013, 24, 804-812.

[7] For nickel-catalyzed carboboration reaction, see: a) A. Yamamoto, M. Suginome, J. Am. Chem. Soc. 2005, 127, 15706-15707; b) M. Suginome, M. Shirakura, A. Yamamoto, J. Am. Chem. Soc. 2006, 128, 14438-14439. For palladium-catalyzed carboboration reaction, see: c) M. Daini, A. Yamamoto, M. Suginome, J. Am. Chem. Soc. 2008, 130, 2918-2919. For copper-catalyzed carboboration reactions, see: d) Y. Okuno, M. Yamashita, K. Nozaki, Angew. Chem. 2011, 123, 950-953; Angew. Chem., Int. Ed. 2011, 50, 920-923; e) R. Alfaro, A. Parra, J. Alemán, J. L. García Ruano, M. Tortosa, J. Am. Chem. Soc. 2012, 134, 15165-15168; f) H. Yoshida, S. Kawashima, Y. Takemoto, K. Okada, J. Ohshita, K. Takaki, Org. Lett. 2013, 15, 952-955; g) Y. Zhou, W. You, K. B. Smith, M. K. Brown, Angew. Chem. 2014, 126, 3543-3547; Angew. Chem., Int. Ed. 2014, 53, 3475-3479. For copper-palladiumcocatalyzed carboboration reaction, see: h) K. Semba, Y. Nakao, J. Am. Chem. Soc. 2014, 136, 7567-7570.

[8] For recent examples, see: a) D. Noda, Y. Sunada, T. Hatakeyama, M. Nakamura, H. Nagashima, J. Am. Chem. Soc. 2009, 131, 6078-6079; b) T. Hatakeyama, T. Hashimoto, Y. Kondo, Y. Fujiwara, H. Seike, H. Takaya, Y. Tamada, T. Ono, M. Nakamura, J. Am. Chem. Soc. 2010, 132, 10674-10676; c) T. Hatakeyama, R. Imayoshi, Y. Yoshimoto, S. K. Ghorai, M. Jin, H. Takaya, K. Norisue, Y. Sohrin, M. Nakamura, J. Am. Chem. Soc. 2012, 132, 20262-20265.

[9] For selected recent examples of iron-catalyzed cross-coupling reactions reported by other groups, see: a) A. Fürstner, R. Martin, H. Krause, G. Seidel, R. Goddard, C. W. Lehmann, J. Am. Chem. Soc. 2008, 130, 8773-8787; b) C. J. Adams, R. B. Bedford, E. Carter, N. J. Gower, M. F. Haddow, J. N. Harvey, M. Huwe, M. A. Cartes, S. M. Mansell, C. Mendoza, D. M. Murphy, E. C. Neeve, J. Nunn, J. Am. Chem. Soc. 2012, 134, 10333-10336; c) M. Guisán-Ceinos, F. Tato, E. Buñuel, P. Calle, D. J. Cárdenas, Chem. Sci. 2013, 4, 1098-1104; d) C. W. Cheung, P. Ren, X. Hu, Org. Lett. 2014, 16, 2566-2569.

[10] a) M. Nakamura, A. Hirai, E. Nakamura, J. Am. Chem. Soc. 2000, 122, 978-979; b) M. Nakamura, K. Matsuo, A. Hirai, E. Nakamura, Org. Lett. 2003, 5, 1373-1375; c) S. Ito, T. Itoh, M. Nakamura, Angew. Chem. 2011, 123, 474-477; Angew. Chem. Int. Ed. 2011, 50, 454-457.

[11] For the hydroboration of alkynes catalyzed by low-valent iron species, see: a) M. Haberberger, S. Enthaler, Chem.-Asian J. 2013, 8, 50-54; b) M. D. Greenhalgh, S. P. Thomas, Chem. Commun. 2013, 49, 11230-11232.

[12] All the reactions were conducted using well-dried glassware under argon. The presence of water or a proton source caused the hydroboration of alkyne, probably by the protonation of alkenyliron(II) intermediates. We demonstrated the selective hydroboration of 4octyne in the presence of methanol. See SI for details.

[13] Terminal alkynes did not participate in the diboration reaction because of competition of the trimerization of alkynes triggered by the deprotonation of terminal alkynes; see: X. Bu, Z. Zhang, X. Zhou, Organometallics 2010, 29, 3530-3534.

[14] Less sterically hindered MeOBnep showed higher reactivity than MeOBpin. See: ref. 1, pp. 16-23.

[15] a) T. Hatakeyama, N. Nakagawa, M. Nakamura, Org. Lett. 2009, 11, 4496-4499; b) T. Hashimoto, T. Hatakeyama, M. Nakamura, J. Org. Chem. 2012, 77, 1168-1173.

[16] Under copper catalysis conditions, secondary alkyl halides could not participate in the carboboration reaction; see: refs. $7 \mathrm{~d}-7 \mathrm{~h}$.

[17] The carboboration of 1-phenyl-1-hexyne with bromocyclohexane proceeded with a moderate regioselectivity $(3.5: 1)$. See SI for details.

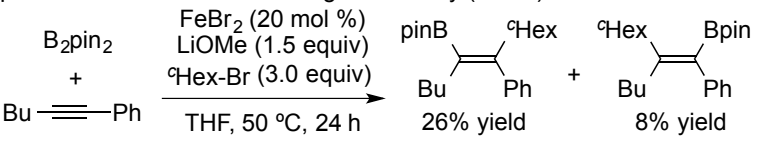


[18] A premix of $\mathrm{FeBr}_{2}$ and a base was necessary for the diboration reaction to generate alkoxyiron as catalytically active species: R. W. Adams, E. Bishop, R. L. Martin, G. Winter, Aust. J. Chem. 1966, 19, 207-210. See SI for details.

[19] The reaction coordinate was investigated for the high-spin state $(\mathbf{A}: \mathbf{S}=$ 4, others: $\mathbf{S}=2$ ) because $\mathbf{A}$ and $\mathbf{B}$ are stable in the high-spin state by $>20 \mathrm{kcal} / \mathrm{mol}$, compared to those in the low- and intermediate-spin states. See SI for details. 


\section{Entry for the Table of Contents}

\section{COMMUNICATION}

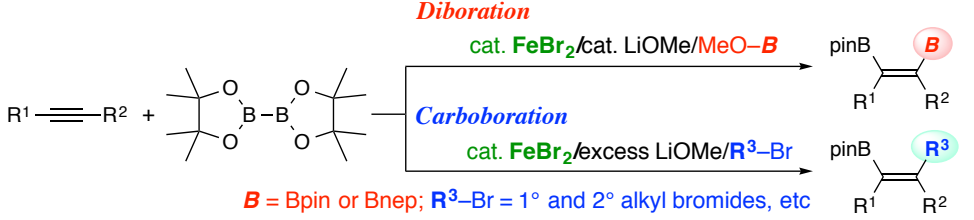

Iron-catalyzed diboration and carboboration of internal alkynes have been developed. These processes feature the unique reactivity of iron catalyst: diboration takes place through a borylmetalation/electrophilic substitution reaction and carboboration through a borylmetalation/radical reaction, both providing the products in a highly cis-selective and chemoselective manner.
Naohisa Nakagawa, Takuji Hatakeyama, and Masaharu Nakamura*

Page No. - Page No.

Iron-Catalyzed Diboration and

Carboboration of Alkynes 